\title{
Molecular tracing of white muscardine in Asian corn borer using inter-simple sequence repeat (ISSR) analysis
}

\author{
B.J. Hu ${ }^{1,2}$, L.N. Xü ${ }^{2}$ Z.Y. Zhou ${ }^{2}$, F. Hu ${ }^{2}$, F.G. $\operatorname{Luan}^{1}$, X. Chen ${ }^{1}$ and Z.Z. Li ${ }^{1}$ \\ ${ }^{1}$ Provincial Key Laboratory of Microbial Control, Anhui Agricultural University, Hefei, \\ Anhui, China \\ ${ }^{2}$ Institute of Plant Protection and Agro-Products Safety, \\ Anhui Academy of Agricultural Sciences, Hefei, Anhui, China \\ Corresponding author: Z.Z. Li \\ E-mail: zzli@ahau.edu.cn
}

Genet. Mol. Res. 14 (4): 18720-18730 (2015)

Received August 26, 2015

Accepted October 19, 2015

Published December 28, 2015

DOI http://dx.doi.org/10.4238/2015.December.28.21

ABSTRACT. Beauveria bassiana is a soil fungus that parasitizes arthropod species, and is used to control the Asian corn borer in Northeast China. In this study, B. bassiana was investigated in Xiaoxian County and Baicheng City, and the results were compared with those of Gongzhuling City, where the fungus was not applied. Using the inter-simple sequence repeat (ISSR) molecular marker technique, 198 isolates were extracted from Asian corn borer and other insect cadavers, and soil and air, and two released strains were analyzed to trace the infection source. In Xiaoxian and Baicheng populations, artificially released $B$. bassiana subpopulations were more abundant than indigenous fungi, and the released strains were the main cause of disease in those areas. Artificial B. bassiana displayed positive effect on overwintering of Asian corn borers in corn straw stacks in Xiaoxian County. Indigenous populations in Gongzhuling City showed 
higher genetic variation. In summary, we identified a significant correlation between genetic distance and geographic distance $(P<0.01)$.

Key words: Asian corn borer; Beauveria bassiana; Molecular tracing; Population genetic structure; Inter-simple sequence repeat;

Genetic distance

\section{INTRODUCTION}

Beauveria bassiana ( $B$. bassiana) is an entomopathogenic fungus with broad specificity, capable of infecting over 750 arthropod species (Bidochka et al., 1994). It plays a significant role in the biological regulation of insect populations and is a source of fungal insecticides. In China, $B$. bassiana has been broadly applied to control diverse pests in agriculture and in forestry, both in greenhouses and in the field (Li et al., 2006). The Asian corn borer (ACB), Ostrinia furnacalis Guenée, is a major insect pest that threatens corn production in China. Use of the fungus in the biological control of the ACB has received considerable attention ( $\mathrm{Pu} \& \mathrm{Li}, 1996)$. From as early as the 1920 and 1930s, Metalinkov and Toumanoff (1928), and Lefebvre (1931) separately began to apply $B$. bassiana to control the European corn borer (ECB). Carruthers et al. (1985) established a mathematical model for predicting biological relationships between B. bassiana and the ECB. Xu et al. $(1973,1986,1987)$ confirmed the bio-control capabilities of $B$. bassiana on the ACB, and this has since become the major control approach in Northeast China. A number of different application processes have been tried in China, such as covering corn straw stacks with $B$. bassiana conidial powder. This method increases the number of parasitized larvae in stacks and reduces the number of insects in fields. It is suitable in corn producing regions suffering intermediate levels of crop damage $(<50 \%)$ and is now largely promoted by agricultural departments (Zhang, 2013). For regions with $>50 \%$ damage, this approach was combined with releasing $B$. bassiana in the field during the late whorl stage, to give a control effect of $56.98 \%$ on second generation ACB in summer corn (Pu and Li, 1996).

$B$. bassiana populations were reported to be genetically diverse (Takatsuka, 2007; Fernandes et al., 2009), and host specialization varied among different isolates (Vestergaard et al., 2003). Molecular ecological approaches provide a precise and credible way to investigate genetic diversity and the population genetic structure of $B$. bassiana. These approaches enable in-depth study of artificially induced, or naturally occurring infectious diseases, in order to establish disease characteristics and dynamics, determine sources and spreading routes, and assess bio-control strategies (Zhao et al., 2007). The inter-simple sequence repeat (ISSR) molecular marker technique in the present studyused16-18 artificially synthesized primers that have 2-4 randomly selected nucleotides at the $3^{\prime}$ or 5' flanking regions, for PCR amplification of the repeating sequences. In comparison to other DNA molecular marker methods, ISSR was more easily used and reliable for assessing genetic diversity. In addition, ISSR has been used in previous studies of plants, animals, and fungi (Gupta et al., 1994; Zietkiewicz et al., 1994; Kerrigan et al., 2003; Wang et al., 2005; Takatsuka, 2007; Lihme et al., 2009). ISSR analysis of hundreds of isolates from a silkworm-producing region, allowed Li et al. $(2010,2011)$ to confirm that silkworm diseases are genetically distant from those of pine moths. They found that silkworm diseases always remained indigenous, regardless of whether pine moths surrounding the silkworm nursery were naturally occurring or released populations. These researchers concluded that applying $B$. bassiana to control pine moths in silkworm-producing regions does not adversely affect the silkworm industry (Li et al., 2010, 2011). ISSR is therefore an effective technique for monitoring the incidence and spread of $B$. bassiana. 
A key activity in insect epidemiology research entails the monitoring of the extent and route of disease spread. Long-distance spread of fungal spores has been well documented. Gregory (1968) reported that uredospores of Puccinia striiformis were dispersed over distances ranging from a few centimeters to over a thousand kilometers. During the period from 2000 to 2002, Hovmøller et al. (2008) demonstrated that rapid global spread of two aggressive strains of a wheat rust fungus, $P$. striiformis f. sp. tritici, over three continents (North America, Australia, and Europe), included areas where the occurrence of yellow rust disease in wheat was previously considered insignificant (eastern USA), or even absent (West Australia). Although there is no similar evidence for $B$. bassiana, Elkinton et al. (1991) estimated that $E$. maimaiga spread over $100 \mathrm{~km}$ in one season. Such evidence suggests that the effects of wind critically influence the movement of air-borne fungi such as $B$. bassiana. Large indigenous populations of $B$. bassiana occur in forests (Ding et al., 2004; Zhao et al., 2007), which work together with released fungi to control forest insect pests. $B$. bassiana can live parasitically in insect hosts, or saprophytically in the environment, when host insects are not present (Studdertand Kaya, 1990). B. bassiana can possibly become established in corn plantations from naturally occurring or artificially released fungi. To date, the population dynamics of released and indigenous $B$. bassiana isolates have not been reported, and the sources of natural epidemics are unknown.

In the present study, ISSR markers were employed to investigate the genetic structure of $B$. bassiana. Molecular tracing of the sources of $B$. bassiana was performed for Xiaoxian County (Anhui Province) and Baicheng City (Jilin Province), where it was artificially released for control of the ACB.The data for these two areas were compared with those for Gongzhuling City, where $B$. bassiana was not applied. The results provide a basis for the rational application of $B$. bassiana as a bio-control agent.

\section{MATERIAL AND METHODS}

\section{Study locations}

Three areas, Xianxian, Baicheng, and Gongzhuling were selected for the study (Table 1).

On May 10, 2010, B. bassiana conidial powder was sprayed on corn straw stacks in experimental plots in Baicheng, and on July 25, 2010, granular preparations of $B$. bassiana were applied during the late whorl stage, to experimental plots in Xiaoxian. B. bassiana was not applied to the experimental plots in Gongzhuling.

\begin{tabular}{|c|c|c|c|}
\hline Location & Province & Country & Longitude and latitude \\
\hline Xiaoxian & Anhui & China & N34ํ1', E11656' \\
\hline Baicheng & Jilin & China & $\mathrm{N} 45^{\circ} 43^{\prime}, \mathrm{E} 122^{\circ} 52^{\prime}$ \\
\hline Gongzhuling & Jilin & China & 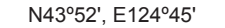 \\
\hline
\end{tabular}

\section{Strains tested}

Two hundred isolates of $B$. bassiana were characterized by ISSR-PCR in the present study. IsolateNo.1 (A1) was a released strain, collected from ACB cadavers in corn fields of Xiaoxian. Taobei District Agricultural Technology Extension Service Center (China) provided the isolation No. 105 (B1), a released strain, isolated from ACB cadavers in Baicheng. The other 198 isolates were 
derived from the cadavers of the insects that were parasitized by the fungus in corn fields, corn straw stacks, soil, and air in the three locations under investigation. Isolations from Xiaoxian (104) were designated as population A,70 isolations from Baicheng as population $B$, and 26 isolations from Gongzhuling as population $C$. The detailed serial numbers, substrates, and collection times of each isolate are listed in Table 2.

Cadavers and soil samples were cultured in selective Dodine-crystal oatmeal medium. Air samples were collected after direct exposure of the selective medium plates to air and culture in Sabouraud-dextrose-yeast extract agar (SDAY) medium (Wang et al., 2000). All B. bassiana isolates were subjected to microscopic and subsequent molecular identification, by ITS1-5.8SITS2 rDNA and Bloc sequencing and preserved in the Anhui Provincial Key Laboratory of Microbial Control (China).

\section{Table 2. Origin of the $B$. bassiana isolates.}

\begin{tabular}{|c|c|c|c|c|}
\hline Population (Locality) & Subpopulation number & Substrate & Collection time & Isolate number \\
\hline \multirow[t]{7}{*}{ A (Xiaoxian County, Anhui Province) } & $\mathrm{A} 1$ & Production strain (released isolate) & & 1 \\
\hline & $\mathrm{A} 2$ & Asian corn borer cadavers in treated field & $16-09-2010$ & $2-30$ \\
\hline & $\mathrm{A} 3$ & $\begin{array}{l}\text { Cadavers of other insects in treated field, } \\
\text { including } 4 \text { Heliothis armigera, } 5 \text { Propylea } \\
\text { japonoca, a chrysopid, } 2 \text { Cryptothelea } \\
\text { variegata and a hemipteran insect }\end{array}$ & $16-09-2010$ & $31-43$ \\
\hline & A4 & Soil in treated field & $16-09-2010$ & $74-84$ \\
\hline & A5 & Air flow above treated field & $16-09-2010$ & $96-104$ \\
\hline & A6 & Asian corn borer cadaver in corn straw stack & $26-05-2011$ & $44-73$ \\
\hline & A7 & Soil beneath corn straw stack & $26-05-2011$ & $85-95$ \\
\hline \multirow[t]{5}{*}{ B (Baicheng City, Jilin Province) } & B1 & Production strain (released isolate) & & 105 \\
\hline & B2 & $\begin{array}{l}\text { Asian corn borer cadavers in stacks treated } \\
\text { with } B \text {. bassiana }\end{array}$ & 03-06-2010 & $106-136$ \\
\hline & B3 & Soil beneath treated corn straw stack & 03-06-2010 & $158-167$ \\
\hline & B4 & Air flow above treated stacks & 03-06-2010 & $168-174$ \\
\hline & B5 & $\begin{array}{l}\text { Asian corn borer cadavers in field near } \\
\text { treated stacks }\end{array}$ & $02-10-2010$ & $137-157$ \\
\hline \multirow[t]{2}{*}{ C (Gongzhuling City, Jilin Province) } & $\mathrm{C} 1$ & Asian corn borer cadavers in stack & 02-06-2010 & $175-191$ \\
\hline & $\mathrm{C} 2$ & Asian corn borer cadavers in field & $01-10-2010$ & $192-200$ \\
\hline
\end{tabular}

\section{Mycelium preparation}

Isolates were inoculated separately on SDAY plates covered with glass paper and incubated in an illuminator at $25^{\circ} \mathrm{C}$ for 4 days, until the petri dishes were fully coved by the of mycelium The thallus was stripped from the glass paper, and mycelia were stored at $-20^{\circ} \mathrm{C}$ following lyophilization.

\section{DNA extractionand screening of ISSR primers}

Total DNA from thallus samples was extracted as described by Zhu et al. (1994) and electrophoresed on $0.8 \%$ agarose gel to determine quality. DNA samples were quantified using SmartSpec plus (Labsystems, Bio-Rad, USA), diluted to $20 \mathrm{ng} / \mu \mathrm{L}$, and stored at $-20^{\circ} \mathrm{C}$. Four $B$. bassiana isolates from each of the three study populations were selected for primer screening, employing the methods of Li et al. (2006) and Yu et al. (2003). Nine of the selected isolates showing clear amplification bands and abundant polymorphisms were selected for PCR amplification (Table 3). 


\begin{tabular}{|c|c|c|c|c|c|c|c|}
\hline Primer & Sequence $\left(5^{\prime}-3^{\prime}\right)$ & $\begin{array}{c}\text { Annealing } \\
\text { temperature }\left({ }^{\circ} \mathrm{C}\right)\end{array}$ & $\begin{array}{c}\text { No. of } \\
\text { amplified loci }\end{array}$ & $\begin{array}{c}\text { No. of } \\
\text { polymorphic loci }\end{array}$ & PPL (\%) & $H_{\mathrm{E}}$ & $I_{\mathrm{s}}$ \\
\hline P5 & $(A A G) 6$ & 48 & 15 & 15 & 100 & $0.3205 \pm 0.1851$ & $0.4768 \pm 0.2362$ \\
\hline P6 & $(A G) 8 S$ & 54 & 14 & 14 & 100 & $0.3299 \pm 0.1767$ & $0.4894 \pm 0.2285$ \\
\hline P10 & (AC)8YC & 52 & 11 & 11 & 100 & $0.2193 \pm 0.2053$ & $0.3401 \pm 0.2706$ \\
\hline P11 & $(\mathrm{AG}) 8 \mathrm{C}$ & 54 & 12 & 12 & 100 & $0.1913 \pm 0.1993$ & $0.3040 \pm 0.2608$ \\
\hline P12 & $\mathrm{TG}(\mathrm{CA}) 6 \mathrm{C}$ & 50 & 13 & 12 & 92.31 & $0.3139 \pm 0.1971$ & $0.4637 \pm 0.2575$ \\
\hline P13 & $\mathrm{CCA}(\mathrm{GTG}) 4$ & 54 & 14 & 13 & 92.86 & $0.2133 \pm 0.1927$ & $0.3339 \pm 0.2583$ \\
\hline P19 & $\mathrm{DD}(\mathrm{CCA}) 5$ & 53.5 & 20 & 20 & 100 & $0.2936 \pm 0.1774$ & $0.4445 \pm 0.2320$ \\
\hline P26 & (GTC)5TC & 54 & 15 & 15 & 100 & $0.2597 \pm 0.1954$ & $0.3990 \pm 0.2496$ \\
\hline P28 & $(A G) 8 Y C$ & 50 & 20 & 20 & 100 & $0.2893 \pm 0.1645$ & $0.4443 \pm 0.2098$ \\
\hline Mean & & & 14.9 & 14.7 & & & \\
\hline Total & & & 134 & 132 & 98.51 & $0.2743 \pm 0.1863$ & $0.4168 \pm 0.2428$ \\
\hline
\end{tabular}

Y represents $\mathrm{C}$ or $\mathrm{T} ; \mathrm{S}$ represents $\mathrm{C}$ or $\mathrm{G}$.

\section{ISSR amplification}

ISSR-PCR amplification was conducted using a Bio-Rad PCR System (T100 ${ }^{\mathrm{TM}}$ Thermal Cycler, USA). PCR buffer (including $25 \mathrm{mM} \mathrm{MgCl}_{2}$ ) and DreamTaq DNA polymerase were purchased from Fermentas (USA), and dNTPs and the GM339 DNA ladder were purchased from Bio Basic (Canada). Primers were synthesized by Jierui Biological Engineering (Shanghai). ISSRPCR amplifications and analyses were conducted as previously described (Wang et al., 2005) with the following modifications: 1.0 U DNA Taq polymerase was decreased to $0.5 \mathrm{U}$, and the template DNA was increased to $20 \mathrm{ng}$. PCR was performed in triplicate. Each PCR reaction contained $1.5 \mu \mathrm{L}$ 10X PCR buffer, 0.25 Mm dNTPs, $0.6 \mu \mathrm{M}$ primers, $0.5 \mathrm{U}$ Taq DNA polymerase, and $20 \mathrm{ng}$ template DNA. The PCR reaction mix was adjusted to a final volume of $15 \mu \mathrm{L}$ with diethylpyrocarbonate (DEPC)-treated water (Sangon Biotech, Sangon). PCR products were separated by $1.5 \%$ agarose gel electrophoresis, visualized, and recorded by using the AlphaEase FC software and the Alpha Imager TM IS-2200 system(USA).

\section{Data analysis}

ISSR electrophoretograms were converted to primitive $(0,1)$ matrices that were subsequently used to calculate: Nei's genetic diversity index $\left(H_{\mathrm{E}}\right)$; Shannon's information index $\left(I_{\mathrm{S}}\right)$; percentage of polymorphic loci $(P P L)$; genetic diversity within population $\left(H_{\mathrm{S}}\right)$; total gene diversity $\left(H_{\mathrm{T}}\right)$; coefficient of genetic differentiation $\left(G_{s t}=H_{\mathrm{T}}-H_{\mathrm{S}} / H_{\mathrm{T}}\right)$; and gene flow $\left[N_{\mathrm{M}}=\left(1-G_{\mathrm{ST}}\right) /\left(4 G_{\mathrm{ST}}\right)\right]$; using POPGENE version32 software (Yeh et al.,1997).

\section{RESULTS}

\section{Polymorphism of ISSR amplification products}

Nine primers showing polymorphism and high stability in ISSR amplification were selected from the initial 23 primers that were screened (Table 3). These nine primers amplified 134 bands from the 200 isolates, of which 132 (98.51\%) were polymorphic. Each primer amplified 11-20 bands, with an average of 14.9. Primers P19 and P28 amplified the highest number (20) of total and polymorphic loci, whereas primer P10 produced the lowest number of amplification products 
(11). Primers P5, P6, P10, P11, P19, P26, and P28 all showed the highest polymorphic percentage $(100 \%)$, and $\mathrm{P} 6$ gave the highest $H_{\mathrm{E}}$ and $I_{\mathrm{S}}$ values.

\section{Genetic consistency and genetic distance in B. bassiana subpopulations}

To determine the genetic relationships between the $B$. bassiana subpopulations in Xiaoxian and Baicheng, POPGENE32 software was employed to survey the genetic similarity $(I)$ and genetic distance $(D)$. The results showed that $D$ was $0.0011-0.1185$ for subpopulations in Xiaoxian, with an average of 0.0381 , whereas I was $0.8883-0.9989$, with an average of 0.9629 (Table 4 ).

\begin{tabular}{|c|c|c|c|c|c|c|c|}
\hline Subpopulation & $\mathrm{A} 1$ & $\mathrm{~A} 2$ & $\mathrm{~A} 3$ & A4 & A5 & A6 & A7 \\
\hline A1 & - & 0.9899 & 0.9650 & 0.9635 & 0.9964 & 0.9314 & 0.8883 \\
\hline A2 & 0.0101 & - & 0.9869 & 0.9797 & 0.9989 & 0.9688 & 0.9343 \\
\hline A3 & 0.0356 & 0.0132 & - & 0.9888 & 0.9803 & 0.9697 & 0.9603 \\
\hline A4 & 0.0372 & 0.0206 & 0.0113 & - & 0.9775 & 0.9553 & 0.9384 \\
\hline A5 & 0.0036 & 0.0011 & 0.0199 & 0.0228 & - & 0.9566 & 0.9249 \\
\hline A6 & 0.0710 & 0.0317 & 0.0307 & 0.0458 & 0.0443 & - & 0.9670 \\
\hline A7 & 0.1185 & 0.0680 & 0.0405 & 0.0635 & 0.0781 & 0.0336 & - \\
\hline
\end{tabular}

Genetic similarity lies above the diagonal and genetic distance lies below the diagonal.

For Baicheng, $D$ was higher than that of Xiaoxian, being 0.0143-0.1006, with an average of 0.0478 . In contrast, I was 0.9043-0.9858, with an average of 0.9537 (Table 5), lower than that of Xiaoxian.

Table 5. Genetic similarity $(I)$ and genetic distance $(D)$ in population B.

\begin{tabular}{|c|c|c|c|c|c|}
\hline Subpopulation & B1 & B2 & B3 & B4 & B5 \\
\hline B1 & - & 0.9832 & 0.9043 & 0.9722 & 0.9279 \\
\hline B2 & 0.0169 & - & 0.9294 & 0.9858 & 0.9638 \\
\hline B3 & 0.1006 & 0.0732 & - & 0.9367 & 0.9549 \\
\hline B4 & 0.0282 & 0.0143 & 0.0654 & - & 0.9786 \\
\hline B5 & 0.0748 & 0.0368 & 0.0461 & 0.0216 & - \\
\hline
\end{tabular}

Genetic similarity lies above the diagonal and genetic distance lies below the diagonal.

Comparison of the released strains (A1 and B1) revealed that isolations from corn fields and stacks, which were treated by these strains (A2 and B2), showed higher I (0.9899 and 0.9832, respectively) and lower $D$ (0.0101 and 0.0169, respectively), which confirmed the insecticidal efficacy of artificially released $B$. bassiana. For both treatments (corn fields and stacks, A2 and $B 2$, respectively), $D$ was similar, whereas / was highest for subpopulations A5 and B4 from airflow samples, suggesting that treatments $A 2$ and $B 2$ contributed to the increased $B$. bassiana density in airflow isolates. In contrast, $D$ was the lowest with subpopulations A7 and B3 from soil for both treatments, suggesting that soil is the primary reservoir of the organism, independent of released strains. This is of great significance to maintaining the genetic diversity of indigenous $B$. bassiana. In addition, ACB cadavers from corn stacks in Xiaoxian (A6) and from the field in Baicheng (B5), gave low $D$ values to subpopulations $A 1$ and $A 2$, and $B 1$ and $B 2$ (just below the values for soil subpopulations $A 7$ and $B 3$ ). These results demonstrate that the cadavers of $A 6$ in corn stacks of Xiaoxian and B5 in Baicheng fields were not caused by artificial release in A1 and B1, but by indigenous strains at the respective locations. 
The $D$ value between subpopulations of Cadavers of other insects (A3) and ACB cadavers (A2) in treated fields in Xiaoxian was markedly lower (0.0132), suggesting that release of $B$. bassiana has some influence on other host insects.

The genetic distance $D$ between different ACB cadaver subpopulations from fields and corn stacks in the three experimental plots are shown in Table 6.

Table 6. Genetic similarity $(I)$ and geographic distance $(D)$ in subpopulations from Asian corn borer cadaver isolates.

\begin{tabular}{lccccrr}
\hline Subpopulation & A2 & A6 & B2 & B5 & C1 \\
\hline A2 & - & 1 & 1949 & 1949 & 1548 & 1548 \\
A6 & 0.0317 & - & 1949 & 1 & 406 & 1548 \\
B2 & 0.3818 & 0.2527 & 0.0368 & - & 406 \\
B5 & 0.3450 & 0.2231 & 0.1609 & 0.1144 & - & 406 \\
C1 & 0.3412 & 0.2377 & 0.1067 & 0.0864 & 0.0716 & - \\
C2 & 0.3905 & 0.2663 & & 1 \\
\hline
\end{tabular}

1) Geographic distance lies above the diagonal and genetic similarity lies below the diagonal. 2) the geographic distance between two subpopulations of the same population is assumed to be $1 \mathrm{~km}$, while the subpopulations of different populations is assumed to be identical: A-B, $1949 \mathrm{~km}$; B-C, $406 \mathrm{~km}$; A-C, $1548 \mathrm{~km}$.

The $D$ values for Xiaoxian (A2-A6) and Baicheng (B2-B5) were 0.0317 and 0.0368 , respectively. Both values were considerably lower than that of C1-C2 in Gongzhuling (0.0716), suggesting that artificial release of $B$. bassiana to control the target species also spread to nontarget species. However, the genetic distance between C1 and C2 in Gongzhuling was lower than that between C1 and B5 (0.1144), C2 and B5 (0.0864), C1 and B2 (0.1609), and C2 and B2 (0.1067) in Baicheng, as well as between C1 and A2 (0.3412), C2 and A2 (0.3905), C1 and A6 (0.2377), and $C 2$ and $A 6(0.2633)$ in Xiaoxian. These results confirm that the genetic distance between populations was significantly correlated with geographic distance $(r=0.894, \mathrm{P}<0.01)$.

\section{Gene flow and genetic differentiation between B. bassiana subpopulations}

POPGENE software was used for further analysis of gene flow and genetic differentiation among the subpopulations of $B$. bassiana. As shown in Table 7, the gene flow $\left(N_{M}\right)$ of subpopulations in Xiaoxian was $0.2999-10.3983$, with an average of 2.1350. The genetic differentiation index $\left(G_{\mathrm{ST}}\right)$ was $0.0235-0.4546$, with an average of 0.1652 (Table 7 ). These results suggest that gene flow varies greatly between $B$. bassiana in different niches.

Table 7. Gene flow $\left(N_{\mathrm{M}}\right)$ and genetic differentiation coefficient $\left(G_{\mathrm{ST}}\right)$ in Population A.

\begin{tabular}{|c|c|c|c|c|c|c|c|}
\hline Subpopulation & $\mathrm{A} 1$ & $\mathrm{~A} 2$ & $\mathrm{~A} 3$ & A4 & A5 & A6 & A7 \\
\hline A1 & - & 2.1796 & 0.6997 & 0.4589 & 2.5484 & 0.7754 & 0.2999 \\
\hline A2 & 0.1029 & - & 3.5161 & 2.0321 & 10.3983 & 2.5887 & 0.9494 \\
\hline A3 & 0.2633 & 0.0664 & - & 3.0388 & 1.8229 & 2.5547 & 1.4539 \\
\hline A4 & 0.3527 & 0.1095 & 0.0760 & - & 1.3037 & 1.5850 & 0.8276 \\
\hline A5 & 0.0893 & 0.0235 & 0.1206 & 0.1609 & - & 1.5411 & 0.6470 \\
\hline A6 & 0.2438 & 0.0881 & 0.0891 & 0.1362 & 0.1396 & - & 2.6143 \\
\hline A7 & 0.4546 & 0.2084 & 0.1467 & 0.2320 & 0.2787 & 0.0873 & - \\
\hline
\end{tabular}

Gene flow $\left(N_{\mathrm{M}}\right)$ lies above the diagonal, and genetic differentiation coefficient is below the diagonal.

ACB cadavers in subpopulation A2 (released strain region) gave the largest $N_{\mathrm{M}}$ but the lowest $G_{\mathrm{ST}}(0.0235)$ in comparison to subpopulation $A 5$ in air, which represented a non-genetic differentiation grade of $<0.05$ according to the criteria of Wright (1931). Released strain A1 and 
subpopulation A7 from soil beneath corn stacks, had the lowest $N_{M}(0.0299)$ and the largest $G_{\text {ST }}$ (0.4546), which represented extensive differentiation of $>0.25$. The gene flow of subpopulations in Baicheng was between 0.4689 and 3.2384 , with an average of 1.5761 , and $G_{S T}$ was between 0.0717 and 0.3478 , with an average of 0.1746 (Table 8).

Table 8. Gene flow $\left(N_{\mathrm{M}}\right)$ and genetic differentiation coefficient $\left(G_{\mathrm{ST}}\right)$ in Population B.

\begin{tabular}{lccccc}
\hline Subpopulation & B1 & B2 & B3 & B4 & B5 \\
\hline B1 & - & 1.5184 & 0.4689 & 0.9355 & 3.2384 \\
B2 & 0.1414 & - & 1.0999 & 1.2033 & - \\
B3 & 0.3478 & 0.1852 & - & 0.17585 \\
B4 & 0.2109 & 0.0717 & 0.1144 & 0.0812 & 2.9347 \\
B5 & 0.3092 & 0.1123 & - \\
\hline
\end{tabular}

Gene flow $\left(N_{\mathrm{M}}\right)$ lies above the diagonal, and genetic differentiation coefficient is below the diagonal.

The gene flow in Baicheng was significantly lower than that in Xiaoxian, but the general trends were consistent. ACB cadavers in subpopulation B2 from the corn stacks showed the largest $N_{\mathrm{M}}$ (3.2384) but lowest $G_{\mathrm{ST}}(0.0717)$, in comparison to subpopulation B4 in air. The released strain B1 showed the lowest $N_{\mathrm{M}}(0.4689)$ but largest $G_{\mathrm{ST}}(0.3478)$, in comparison to subpopulation B3 from soil beneath the corn stacks, reflecting extensive differentiation. These results further confirm that soil is the main reservoir of $B$. bassiana from which new fungal infections can arise and spread.

Released B. bassiana strains and in Xiaoxian (A1) and Baicheng (B1), showed high $N_{\mathrm{M}}$ (2.1796 and 1.5184 , respectively) and low $G_{S T}(0.1029$ and 0.1414 , respectively) with subpopulations $A 2$ and $B 2$ from $A C B$ cadavers in treated regions. This indicates that there was only moderate genetic differentiation between released strains and subpopulations from ACB cadavers in treated regions. This further confirms the colonization effect of $B$. bassiana release, and suggests that the released strains were the main source of fungus in ACB. The $N_{M}$ value between ACB cadavers in the treated field in Xiaoxian (A2) and other subpopulations (cadavers of other insect hosts (A3), soil (A4), air (A5), and corn stacks (A6)) were 3.5161, 2.0321, 10.3983, and 2.5887, respectively. These values were all far higher than the threshold value of 1.0 for gene differentiation, indicating that gene introgression and flow was strengthened. In addition, released $B$. bassiana could be dispersed by ACB cadavers, soil, and air to treated regions. Furthermore, the $N_{M}$ between A2 and $A 3$ was 3.5161 , and $G_{S T}$ was only 0.0664 , suggesting minimal genetic differentiation between the two subpopulations. This finding further demonstrates that release of $B$. bassiana for bio-control has influenced the other insects.

As shown in Table 9, $G_{\mathrm{ST}}$ values of subpopulations A2-A6 and B2-B5 isolated from cadavers in the treated regions of Xiaoxian and Baicheng were 0.0881 and 0.1123 , respectively, reflecting moderate differentiation. These $G_{\mathrm{ST}}$ values were markedly lower than those of the two highly differentiated subpopulations (C1 and C2) in Gongzhuling (0.2045; relative gene flow of 0.9726), which is consistent with the genetic distance analysis. These findings suggest that gene introgression and flow in areas where fungi was artificially released, was more extensive than that in untreated regions, further confirming the influence of released $B$. bassiana for bio-control purposes.

With the exception of B5-C1 and B5-C2, which gave $G_{\mathrm{ST}}$ values of 0.2407 and 0.2190 respectively, $G_{S T}$ values between subpopulations from $A C B$ cadavers were consistently higher than 0.25 , representing extensive differentiation. This indicates that gene flow between subpopulations in the three experimental plots was blocked to a certain extent. The genetic and geographic distance in the three experimental plots were clearly correlated, and likewise, the genetic differentiation index was significantly correlated with geographic distance $(r=0.796, \mathrm{P}<0.01)$. These results 
reflect the regional characteristics of $B$. bassiana widely prevalent in the population of ACB in southern and northern China.

\begin{tabular}{|c|c|c|c|c|c|c|}
\hline Subpopulation & $\mathrm{A} 2$ & A6 & B2 & B5 & $\mathrm{C} 1$ & $\mathrm{C} 2$ \\
\hline A2 & - & 1 & 1949 & 1949 & 1548 & 1548 \\
\hline A6 & 0.0881 & - & 1949 & 1949 & 1548 & 1548 \\
\hline B2 & 0.5686 & 0.3683 & - & 1 & 406 & 406 \\
\hline B5 & 0.4924 & 0.3072 & 0.1123 & - & 406 & 406 \\
\hline C1 & 0.5105 & 0.3329 & 0.3433 & 0.2407 & - & 1 \\
\hline C2 & 0.5730 & 0.3797 & 0.2938 & 0.2190 & 0.2045 & - \\
\hline
\end{tabular}

Geographic distance $(\mathrm{km})$ lies above the diagonal, genetic differentiation coefficient is below the diagonal.

\section{DISCUSSION}

In the present study, the application of granule preparations of $B$. bassiana to corn fields (during the late whorl stage) in Xiaoxian County, and powder preparations of $B$. bassiana to corn stacks in Baicheng City, both resulted in a certain degree of efficacy. The induced epidemics in corn fields and stacks killed a large number of ACBs, but also infected other host insects, soil, and airflow in treated regions. The released strains also infected ACBs in corn stacks in Xiaoxian and corn fields in Baicheng that did not receive artificial B. Bassiana treatment. This suggests that released strains also contribute to the development of enzootics. Disease in untreated areas was likely caused by non-dominant indigenous strains, although dominant strains did contribute to the incidence of endemic disease. This resulted in robust heterogeneous subpopulations within different ecological niches of the two regions, which is favorable for strengthening genetic diversity.

In Gongzhuling, where B. bassiana was not applied, the populations consisted entirely of indigenous organisms that exhibited greater genetic variation (higher genetic distance and genetic differentiation) than isolates from Xiaoxian and Baicheng, both of which had clearly been affected by artificial inoculation. Indigenous fungus causeda low rate of endemic disease in ACB populations, whereas artificial inoculation reduced the number of insects by further enhancing disease. In the present study, we have shown that this limitation may be overcome by artificially releasing $B$. bassiana on corn plants during the late whorl stage, and/or by treating corn stacks.

Analysis of the phylogenetic relationships between $B$. Bassiana from different geographical sources and insect hosts has yielded disparate results. Viaud et al. (1996) and Maurer et al. (1997) reported that the host, rather than the geographic source, determines the phylogeny of $B$. bassiana, whereas Berretta et al. (1998) and Gaitan et al. (2002) found no correlation between host and source. However, more recent studies do suggest that geographical source determines phylogeny (Bidochka et al.,1997; Wang et al., 2003; Aquino de Muro et al., 2005; Wang et al., 2005). The sample sizes in the aforementioned studies were limited; therefore, He et al. (2012) and Hu et al. (2013) separately investigated B. bassiana populations in 622 isolates from 13 provinces, and 568 isolates from 9provinces, in northern and southern China respectively, using the ISSR technique. Both studies reported that regional differences in phylogeny could only be detected in large sample populations (almost the entire northern or southern regions of China). Phylogeny across subpopulations within small populations indicates a random arrangement and combination, regardless of geographic distance, neighboring relationship, or phylogenetic relationship of host insects. In the present study, we found clear regional characteristics in phylogeny using only 200 
isolates, and identified a significant correlation between genetic distance and geographic distance $(P<0.01)$. This could be because our study involved only one host insect $(A C B)$ in the three experimental plots. Given an increased number of experimental plots and/or insect hosts, the phylogeny may become scrambled in a larger dataset. This hypothesis remains to be tested.

In addition, ACBs have a different voltinism in Jilin Province and Anhui Province. Populations in Baicheng and Gongzhuling exhibited digoneutism, whereas in Xiaoxian, trigoneutism was common. The genetic relationships between the subpopulations of cadavers of ACBs in Baicheng (B2 and B5) and the subpopulations in Gongzhuling (C1 and C2), were found to be closer than those between the subpopulations in Baicheng and Gongzhuling (B2, B5, C1, and C2) and the subpopulations in Xiaoxian (A2 and A6). Whether this was related to their differences in voltinism requires further investigation.

\section{Conflicts of interest}

The authors declare no conflict of interest.

\section{ACKNOWLEDGMENTS}

Research supported by a grant from the Natural Science Foundation of China (\#30972368). We are grateful to Xiangyang Wang and Yunfeng Tan for their help during field investigations and Shengli Zhang for his technical assistance with laboratory work.

\section{REFERENCES}

Aquino de Muro M, Elliott S, Moore D, Parker BL, et al. (2005). Molecular characterisation of Beauveria bassiana isolates obtained from overwintering sites of Sunn pests (Eurygaster and Aelia species). Mycol. Res. 109: 294-306.

Berretta MF, Lecuona RE, Zandomeni RO and Grau O (1998). Genotyping Isolates of the Entomopathogenic Fungus Beauveria bassiana by RAPD with Fluorescent Labels. J. Invertebr. Pathol. 71: 145-150.

Bidochka MJ, McDonald MA, St Leger RJ and Roberts DW (1994). Differentiation of species and strains of entomopathogenic fungi by random amplification of polymorphic DNA (RAPD). Curr. Genet. 25: 107-113.

Bidochka MJ, Walsh SRA, Ramos ME, St Leger RJ, et al. (1997). Cloned DNA probes distinguish endemic and exotic Entomophaga grylli fungal pathotype infections in grasshopper life stages. Mol. Ecol. 6: 303-308.

Carruthers RI, Feng Z, Robson DS and Roberts DW (1985). In vivo temperature-dependent development of (Deuteromycotina: Hyphomycetes) mycosis of the European corn borer, (Lepidoptera: Pyralidae). J. Invertebr. Pathol. 46: 305-311.

Ding DG, Li ZZ, Fan MZ and Wang B (2004). Host transfer of Beauveria bassiana population in pine stand ecosystem and impact of its genetic diversity on sustainable control of Masson's pine caterpillars. Chin. J. Appl. Ecol. 15: 2315-2320.

Elkinton JS, Hajek AE, Boettner GH and Simons EE (1991). Distribution and apparent spread of Entomophaga maimaiga (Zygomycetes: Entomophthorales) in Gypsy moth (Lepidoptera: Lymantriidae) populations in North America. Environ. Entomol. 20: 1601-1605.

Fernandes EKK, Moraes AML, Pacheco RS, Rangel DEN, et al. (2009). Genetic diversity among Brazilian isolates of Beauveria bassiana: comparisons with non-Brazilian isolates and other Beauveria species. J. Appl. Microbiol. 107: $760-774$.

Gaitan A, Valderrama AM, Saldarriaga G, Velez P, et al. (2002). Genetic variability of Beauveria bassiana associated with the coffee berry borer Hypothenemus hampei and other insects. Mycol. Res. 106: 1307-1314.

Gregory PH (1968). Interpreting plant disease dispersal gradients. Annu. Rev. Phytopathol. 6: 189-212.

Gupta M, Chyi Y, Romero-Severson J and Owen J (1994). Amplification of DNA markers from evolutionarily diverse genomes using single primers of simple-sequence repeats. Theor. Appl. Genet. 89: 998-1006.

He LM, Hu XL, Chen X, Zhang SL, et al. (2012). Genetic Diversity and Population Genetic Structure of Beauveria bassiana in Northern China. Chin. J. Appl. Ecol. 23: 3087-3095.

Hovmøller MS, Yahyaoui AH, Milus EA and Justesen AF (2008). Rapid global spread of two aggressive strains of a wheat rust fungus. Mol. Ecol. 17: 3818-3826.

Hu XL, He LM, Chen X, Zhang SL, et al. (2013). Genetic Diversity and Population Genetic Structure of Beauveria bassiana in 
South China. Chin. J. Biol. Control 1: 31-41.

Kerrigan J, Smith MT, Rogers JD, Poot GA, et al. (2003). Ascobotryozyma cognata sp. nov., a new ascomycetous yeast associated with nematodes from wood-boring beetle galleries. Mycol. Res. 107: 1110-1120.

Lefebvre CL (1931). Preliminary observations on two species of Beauveria attacking the corn borer, Pyrausta nubilalis Hubner. Phytopathology 21: 1115-1128.

Li JL, Cai Y, Luan FG, Wang B, et al. (2010). Population genetic structure of Beauveria bassiana from south and southwest Anhui sericultural regions: ISSR analysis. Chin. J. Appl. Ecol. 21: 3239-3247.

$\mathrm{Li} \mathrm{JL}$, Luan FG and Li ZZ (2011). Tracing of the origin and the spreading track of silkworm white muscardine in southwestern Anhui. Sci. Agr. Sin. 44: 143-152.

Li M, Wang SB, Fan MZ, Li ZZ, et al. (2006). Genetic Diversity of Beauveria bassiana (Bals.) Vuill. in Forest Ecosystem Assessed by Inter-simple Sequence Repeat (ISSR) Markers. Hereditas 28: 977-983.

Lihme M, Jensen AB and Rosendahl S (2009). Local scale population genetic structure of Entomophthora muscae epidemics. Fungal Ecol. 2: 81-86.

Maurer P, Couteaudier Y, Girard PA and Riba G (1997). Genetic diversity of Beauveria bassiana and relatedness to host insect range. Mycol. Res.101: 159-164.

Pu ZL and Li ZZ (1996). Insect mycology. Anhui Publishing House of Science \& Technology, Hefei, China.

Studdert JP and Kaya HK (1990). Water potential, temperature, and soil type on the formation of Beauveria bassiana soil colonies. J. Invertebr. Pathol. 56: 380-386.

Takatsuka J (2007). Characterization of Beauveria bassiana isolates from Japan using inter-simple-sequence-repeat-anchored polymerase chain reaction (ISSR-PCR) amplification. Appl. Entomol. Zool. 42: 563-571.

Vestergaard S, Cherry A, Keller S and Goettel M (2003). Safety of hyphomycete fungi as microbial control agents. In: Environmental impacts of microbial insecticides: need and methods for risk assessment (Hokkanen HMT and Hajek AE, eds.). Kluwer Academic Publishers, Dordrecht, 35-62.

Viaud M, Couteaudier Y, Levis C and Riba G (1996). Genome organization in Beauveria bassiana: Electrophoretic karyotype, Gene mapping, and Telomeric fingerprint. Fungal Genet. Biol. 20: 175-183.

Wang B, Fan MZ and Li ZZ (2000). Sieving of selective media for Beauveria bassiana. J. Anhui Agr. Univ. 27: 23-28.

Wang CS, Shah FA, Patel N, Li ZZ, et al. (2003). Molecular investigation on strain genetic relatedness and population structure of Beauveria bassiana. Environ. Microbiol. 5: 908-915.

Wang S, Miao X, Zhao W, Huang B, et al. (2005). Genetic diversity and population structure among strains of the entomopathogenic fungus, Beauveria bassiana, as revealed by inter-simple sequence repeats (ISSR). Mycol. Res.109: 1364-1372.

Wright S (1931). Evolution in Mendelian populations. Genetics 16: 97-159.

Xu QF, Zhang R, Gui CM, Han YM, et al. (1973). Field application with Beauveria bassiana for Asian borer control. Acta Entomol. Sin. 16: 203-206.

Xu QF, Song YL and Du CX (1986). Field experiments on Beauveria bassiana (strain \#147 and \#9) to control Asiatic corn borer. Chin. J. Biol. Control 2: 14-16.

Xu QF, Song YL, Du CX, Yang MZ, et al. (1987). An investigation of culturing the fungus pathogen, Beauveria bassiana in maize whorl against corn borer (Ostrinia furnacalis). J. Jilin Agr. Sci. 4: 23-27.

Yeh F, Yang R, Boyle T, Ye Z, et al. (1997). POPGENE, the User-friendly Shareware for Population Genetic Analysis. Molecular Biology and Biotechnology Centre, University of Alberta, Edmonton http://www.ualberta.ca/ fyeh/popgene_download.html.

Yu Y, Chen HS and Ge XJ (2003). Optimization of experiment conditions and primer screening with ISSR markers. J. Trop Sub. Botany 11: 15-19.

Zhang K (2013). Test of Beauveria bassiana in corn stalk-stubble piles for controlling corn borers. Mod. Agr. Sci. Technol. 7: 135.

Zhao XQ, Cai SP, Wang SB, Wang L, et al. (2007). Evidence of survival and sustainable control on pests of Beauveria bassiana after artificial release in Massion pine plantation. Mycosystema 26: 84-88.

Zhu H, Qu F and Zhu LH (1994). Isolation of genomic DNAs from Fungi using benzyl chloride. Acta Mycol. Sin. 13: 34-40.

Zietkiewicz E, Rafalski A and Labuda D (1994). Genome fingerprinting by simplesequence repeat (SSR)-anchored polymerase chain reaction amplification. Genomics 20: 176-183. 